\title{
Evaluation and treatment of facial feminization surgery: part I. forehead, orbits, eyebrows, eyes, and nose
}

\author{
Brian N. Dang, Allison C. Hu, Anthony A. Bertrand, Candace H. Chan, Nirbhay S. Jain, \\ Miles J. Pfaff, James C. Lee, Justine C. Lee \\ Division of Plastic and Reconstructive Surgery, University of California Los Angeles David Geffen School of Medicine, Los Angeles, CA, USA
}

Facial feminization surgery (FFS) incorporates aesthetic and craniofacial surgical principles and techniques to feminize masculine facial features and facilitate gender transitioning. A detailed understanding of the defining male and female facial characteristics is essential for success. In this first part of a two-part series, we discuss key aspects of the general preoperative consultation that should be considered when evaluating the prospective facial feminization patient. Assessment of the forehead, orbits, hairline, eyebrows, eyes, and nose and the associated procedures, including scalp advancement, supraorbital rim reduction, setback of the anterior table of the frontal sinus, rhinoplasty, and soft tissue modifications of the upper and midface are discussed. In the second part of this series, bony manipulation of the midface, mandible, and chin, as well as soft tissue modification of the nasolabial complex and chondrolaryngoplasty are discussed. Finally, a review of the literature on patient-reported outcomes in this population following FFS is provided.

Keywords Facial feminization surgery / Transgender persons / Gender affirming surgery / Gender dysphoria
Correspondence: Justine C. Lee Division of Plastic and Reconstructive Surgery, University of California Los Angeles David Geffen School of Medicine, 200 Medical Plaza, Suite 460, Los Angeles, CA 90095, USA Tel: +1-310-794-7616

Fax: +1-310-206-6833

E-mail: justine@ucla.edu

\begin{abstract}
All sources of funds supporting the completion of this manuscript are under the auspices of the University of California Los Angeles. This work was supported by the Bernard G. Sarnat Endowment for Craniofacial Biology (JCL). JCL is additionally supported by the Jean Perkins Foundation and the National Institutes of Health/National Institute of Dental and Craniofacial Research R01 DE028098 (JCL) and R01 DE029234 (JCL).
\end{abstract}

The authors thank Amanda K. Ho (NASA Jet Propulsion Laboratory, Pasadena, CA, USA) for her contributions to Fig. 1.

Received: January 20, 2021 - Revised: June 19, 2021 • Accepted: July 12, 2021

pISSN: 2234-6163 • elSSN: 2234-6171 • https://doi.org/10.5999/aps.2021.00199• Arch Plast Surg 2021;48:503-510

\section{INTRODUCTION}

Facial gender confirmation surgery, commonly known as feminization surgery, incorporates aesthetic and craniofacial surgical principles and techniques to feminize masculine facial features and facilitate gender transitioning. The prioritization of facial feminization surgery (FFS) over other forms of gender reassign- ment surgery among transgender individuals reflects the important role it plays in gender dysphoria $[1,2]$. Studies such as those by Ainsworth and Spiegel [3], and more recently by Morrison et al. [4], have revealed its positive effects on mental health-related quality of life. Objective studies of public perception have also demonstrated significant differences in gender appearance from FFS beyond what hormone or non-surgical therapy can 
provide [5]. Though a majority of transgender individuals desire surgical transitioning, only $25 \%$ have access to do so [6]. Increasing awareness, scientific information sharing, and formal training in the field $[7,8]$ will drive surgical innovation and patient advocacy to improve outcomes and address the unmet healthcare needs in this population.

FFS encompasses a broad range of procedures unique to transgender patients. In this review, we present an in-depth analysis of the current literature on FFS. This first section of a two-part series describes the preoperative evaluation process and focuses on management of the hairline, forehead, orbits, eyebrows, eyes, and nose.

\section{GENERAL PREOPERATIVE EVALUATION}

The World Professional Association for Transgender Health Standards of Care version 7 considers chest and genital surgery as medically necessary, but lacks set guidelines for the clinical evaluation and management of patients who wish to undergo FFS [9]. At our institution, patients undergoing FFS require preoperative evaluation by a multidisciplinary gender health team. The diagnosis of gender dysphoria is first determined by a gender health specialist or mental health provider. As gender dysphoria is highly individualized, the timing of medical and surgical transition varies among patients; some choose to undergo hormonal therapy for many years prior to FFS while others choose to have FFS as their first intervention in transitioning. Letters of support for FFS from a mental health provider as well as from the patient's primary care physician or gender health specialist, albeit not explicitly required for insurance ap- proval, are frequently used to demonstrate the medical necessity of FFS for the patient. Preoperative clearance by a primary care provider is typically desired.

At the time of consultation, a discussion about the patient's ideal features and goals as well as the risks, benefits, expectations, and limitations of surgery must be carried out [10]. A thorough physical examination should be performed, including assessment of facial anthropometrics, ascertaining baseline neuromuscular function, and obtaining standardized preoperative photographs. It is important to remember that many of the "standard" measurements reported in the literature are based on Caucasian profiles and therefore ethnicity and age should be taken into consideration during the planning phase [11].

For individuals requiring bony manipulation, a fine-cut, noncontrast craniofacial computed tomography scan from the vertex to the hyoid bone is helpful to map the bony framework. Virtual surgical planning may further assist with craniofacial anatomical mapping by developing prefabricated cutting guides and models that facilitate planning, reduce operating time, and improve outcomes [12-14]. Recently, our group published a method of simplification of FFS via modeling on a reference female skull [12]. The key anthropomorphic differences between the upper two-thirds of the male and female faces are outlined in Table 1 and Fig. 1.

\section{FOREHEAD AND ORBITS}

\section{Clinical evaluation}

The clinical exam of the forehead begins with the hairline. While the male hairline typically has a characteristic M-shape secondary to male-pattern hair loss, the female hairline is often round-

Table 1. Comparison of typical male and female facial characteristics

\begin{tabular}{|c|c|c|}
\hline Facial feature & Male & Female \\
\hline \multirow[t]{3}{*}{ Hairline } & M-shaped hairline & 0-shaped hairline \\
\hline & Presence of temporal recession & Absence of temporal recession \\
\hline & Long non-hair bearing forehead $(6-8 \mathrm{~cm})$ & Short non-hair bearing forehead $(\sim 5 \mathrm{~cm})$ \\
\hline \multirow[t]{4}{*}{ Forehead } & Sloped with concavity superior to supraorbital ridge & Round/convex without concavity superior to supraorbital ridge \\
\hline & Prominent projection of supraorbital ridge & Minimal projection of supraorbital ridge \\
\hline & Sagittal position of the globe with respect to the brow ridge $>10 \mathrm{~mm}$ & Sagittal position of the globe with respect to the brow ridge $<10 \mathrm{~mm}$ \\
\hline & Temporal hollowing & Temporal fullness \\
\hline Orbit & Small aperture & Round with wide aperture \\
\hline Eyebrows & Flat eyebrows sitting at supraorbital ridge & Curved eyebrows with lateral limbus peaking superior to supraorbital ridge \\
\hline \multirow[t]{2}{*}{ Eyes } & Increased intercanthal distance & Decreased intercanthal distance \\
\hline & Elevated supratarasal crease (8-11 mm) & Low supratarsal crease (6-9 mm) \\
\hline \multirow[t]{5}{*}{ Nose } & Nasofrontal angle $\sim 130^{\circ}$ & Nasofrontal angle $\sim 145^{\circ}$ \\
\hline & Wide and large dorsal hump with straight dorsal lines & Narrow and small dorsal hump with curved dorsal lines \\
\hline & Radix at upper lid crease increased nasal tip projection & Radix at mid-pupillary line decreased nasal tip projection \\
\hline & Nasolabial angle $\sim 90^{\circ}-95^{\circ}$ & Nasolabial angle $\sim 100^{\circ}-105^{\circ}$ \\
\hline & Wide alar base & Narrow alar base \\
\hline
\end{tabular}


ed. The mean length of the non-hair-bearing forehead for males is approximately $6.6 \mathrm{~cm}$ compared to $5 \mathrm{~cm}$ in females [15].

On lateral view, the male forehead tends to slope flatly down to a prominence at the superior orbital ridge. On sagittal view, the orbit is typically measured at $10 \mathrm{~mm}$ (or more) posterior to the superior orbital ridge. In contrast, the female forehead is flat or slightly convex with the orbit less than $10 \mathrm{~mm}$ posterior to the superior orbital ridge on sagittal view [15]. Additionally, the female orbit is round with a wider aperture than the male, producing a softer appearance $[16,17]$. Gender differences in the
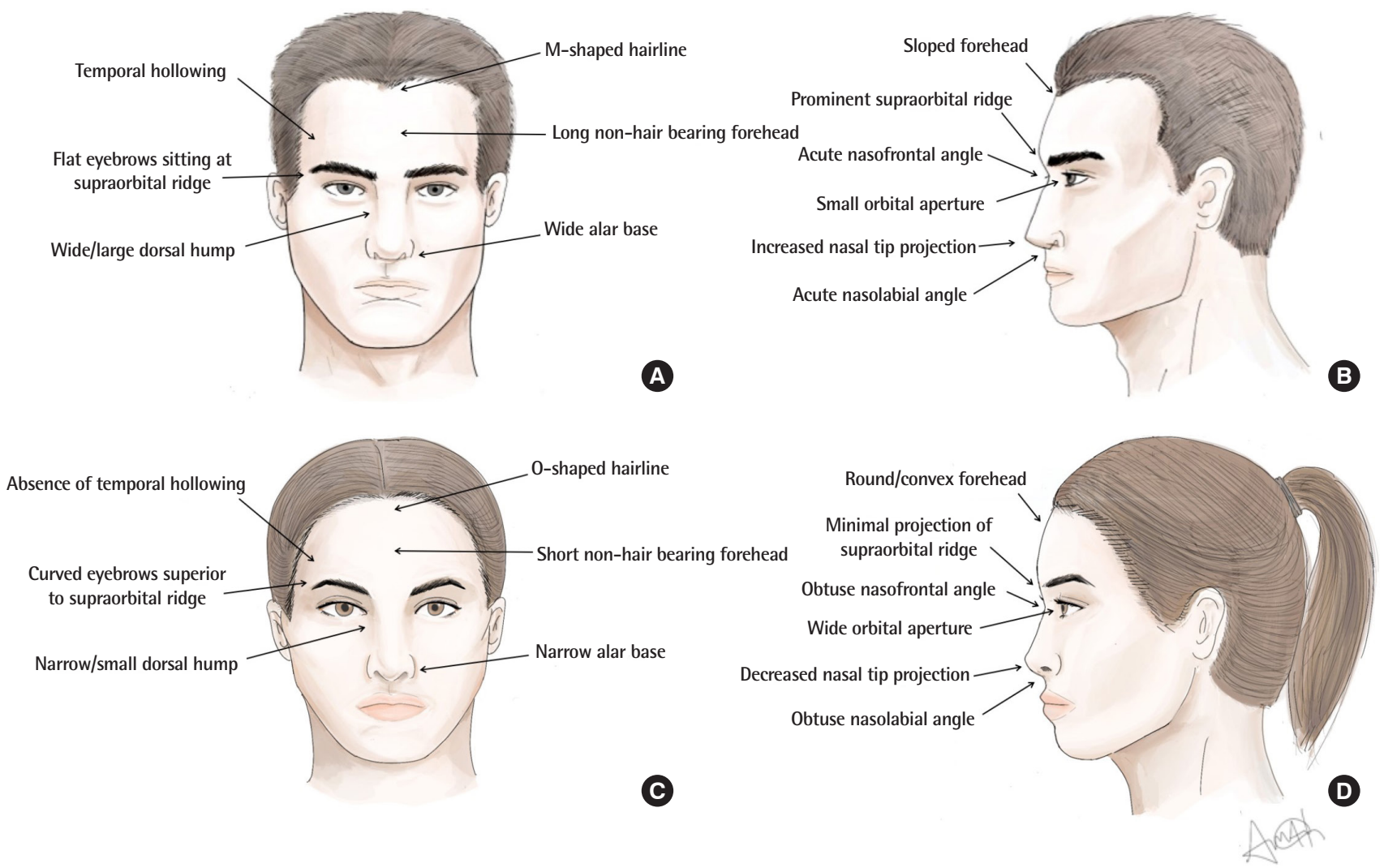

Fig. 1. Typical male and female face. (A) Frontal view and (B) lateral view of male face. (C) Frontal view of and (D) lateral view of female face.

Type I

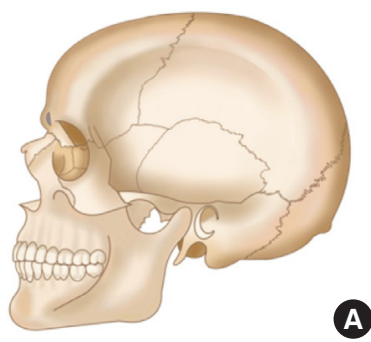

Type III

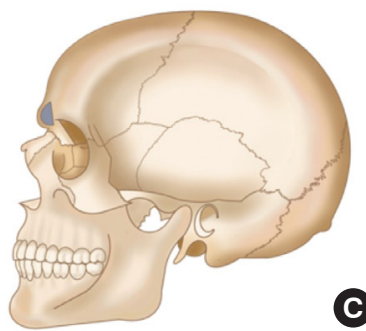

Type II

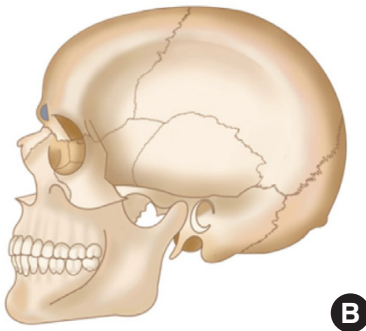

Type IV

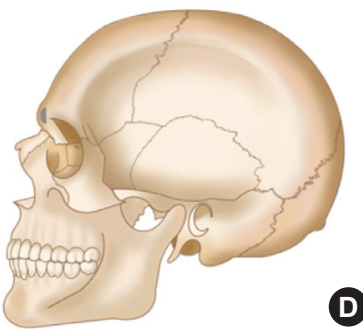

Fig. 2. Forehead classification according to Ousterhout [15]. (A) Type I forehead morphology (8\%-9\%) is characterized by a mild to moderate projection of the brow, thickened layer of bone anterior to the frontal sinus, and possible absence of the frontal sinuses. The desired contour is achieved with burring alone. (B) Type II (8\%-9\%) forehead morphology includes mild to moderate projection of the brow, a thin anterior table of the frontal sinus, and a possible area of concavity superior to the supraorbital rim. Treatment options include burring of frontal bossing (but special care to not enter the frontal sinus) or augmentation of the concavity. (C) Type III (82\%) forehead morphology includes an excessive anterior projection of the brows and treatment consists of osteotomy and setback of anterior table of the frontal sinus. (D) Type IV (1\%) forehead morphology is characterized by a severely diminutive forehead and treatment requires augmentation of the entire forehead. 
forehead soft tissue are also apparent, as females tend to have less temporal hollowing compared to males [18]. Dimensions of the frontal sinus and thickness of the anterior table can be determined from preoperative computed tomography scans prior to surgery. Forehead morphology and recommended management can be classified according to Ousterhout (Fig. 2) [15].

\section{Hairline advancement, frontal bone reduction, and orbit manipulation}

Hairline advancement and frontal bone reduction is generally performed simultaneously, though both procedures have significant variations according to surgeon preference. In the process of altering the frontal bone, the orbit is also manipulated to achieve a more feminine appearance.

When indicated, hairline advancement reduces the length of the non-hair-bearing forehead through a pretrichial coronal incision extending posteriorly in the temporal scalp and inferiorly down to the post-auricular region [19]. The dissection proceeds posteriorly in either a subgaleal or subperiosteal plane to the occiput in order to maximally advance the scalp. Galeotomies and intraoperative tissue expansion can be utilized to gain further advancement, although care must be taken to preserve the scalp vascular plexus in the subcutaneous connective tissue layer. Anterior dissection is also performed to expose the frontal bone just distal to the nasofrontal junction, superior orbital rims, and zygomaticofrontal sutures. Care must be taken to avoid injury to the frontal branch of the facial nerve lying superficial to the deep temporal fascia during the dissection over the temporal scalp.

Other techniques to modify the hairline include simultaneous hair transplantation with forehead reconstruction using two modified coronal approaches $[20,21]$. There are some differing opinions with respect to the timing of hair transplantation, with some groups recommending immediate transplantation [20] and others suggesting that deferred hair transplantation improves engraftment rates [22] and results in fewer complications $[19,23]$. Although some argue that hair transplantation is superior to hairline lowering surgery [20], a consensus has not been reached.

In the absence of any need for hairline lowering, a typical bicoronal incision is performed. Regardless of incision design, management of the frontal bone is often based off the standardized approach described by Ousterhout's classification (Fig. 2) [15]. Group I foreheads ( $8 \%-9 \%$ of patients) have mild brow bossing, thus burring alone is sufficient for correction. Group II foreheads ( $8 \%-9 \%)$ have moderate forehead and brow bossing with characteristic flattening superiorly. These patients require a combination of burring with augmentation of the flattened portion with autologous or allogenic substances. Group III fore-
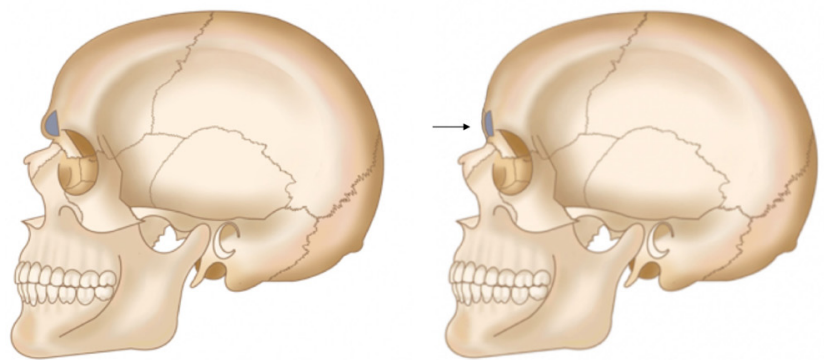

Fig. 3. Type III anterior table of the frontal sinus setback. In the majority of patients, the type III forehead operation as described by Ousterhout will be necessary. In this operation, the anterior table of the frontal sinus is osteotomized and reshaped on the backtable to flatten the contour (black arrow). Simultaneously, the frontal bone is contoured and the superior orbital rims are reduced laterally to the zygomaticofrontal suture. Medially, the radix is reduced to ensure a smooth transition between the frontal bone and the nose. Following completion of frontal bone contouring, the anterior table is replaced and stabilized with titanium plates and screws in its new setback position.

heads ( $82 \%$ ) have moderate to severe forehead and brow bossing, requiring an osteotomy of the anterior table of the forehead and setback, in addition to burring of the superior orbital rim (Fig. 3) [3]. Lastly, group IV foreheads (1\%) [24] are characterized by such a slope that setback cannot achieve the necessary contour. Thus, augmentation with autogenous bone or with alloplastic materials, such as methylmethacrylate, polyethylene, or hydroxyapatite cement, is needed to establish forehead convexity [15,25-27]. In the senior author's (JCL) experience, $90 \%$ of patients require frontal bone osteotomy and setback.

\section{Temples and soft tissue}

Temporal fossa augmentation can be achieved with either hyaluronic acid fillers, autologous fat, or implants [28]. Patients may also elect for myectomies of the galea-frontalis, procerus, and corrugator muscles to further reduce wrinkling of the forehead, minimize prominence of the muscles, and facilitate facial rejuvenation and feminization [29].

Manipulation of the frontal sinus and forehead recontouring should be carried out with proper care and training to avoid postoperative complications. Temporary paresthesia in the distribution of the supraorbital nerves and edema of the upper eyelid are common. Cerebrospinal fluid rhinorrhea may also occur if the frontal sinus osteotomy is too high, damaging the dura and penetrating the posterior table [30]. While infection rates or mucocele formation appear to be low [23], latent mucoceles may go undetected until several years after surgical manipulation of the sinus [31]. Future studies focusing on the long-term effects of frontal sinus setback and role of sinus functionalization are necessary to better characterize these potential complications. 


\section{EYEBROWS AND EYES}

\section{Clinical evaluation}

Male eyebrow morphology tends to be straight and flat, sitting at the level of the supraorbital ridge with increased intercanthal distance compared to females $[19,32]$. The female eyebrow is curved in shape and tends to sit superior to the supraorbital ridge [19], peaking at approximately $1 \mathrm{~cm}$ above the ridge at the lateral limbus with a positive canthal tilt [33]. In Caucasian males, the supratarsal crease lies $8-11 \mathrm{~mm}$ above the upper eyelid, while in Caucasian females, the distance is about 6-9 $\mathrm{mm}$ [32]. Ethnic considerations must be noted during evaluation and operative planning to preserve the patient's ethnic identity $[34,35]$.

\section{Eyebrows}

Although the brows are naturally modified during bony reduction of the supraorbital ridge and when the hairline is lowered via skin excision, a brow lift can better control brow morphology to achieve a more feminine appearance [36]. A number of methods have been reported to supplement temporal brow lifting from soft tissue excision. Our group prefers to use suture suspension with bone channels created in the outer table of the frontal bone superior to the brows beneath the hairline. Others have described brow lift techniques using various forms of suture anchors [37].

\section{Eyes}

While bony modifications of the orbital rims during forehead recontouring augment the appearance of the eyes, soft tissue modifications to this region may be beneficial as a supplementary procedure for certain patients. A lateral canthopexy can change canthal tilt to achieve a more feminine appearance $[33,38]$. While not specifically for the purposes of gender affirmation, both upper and lower blepharoplasties may be beneficial for optimal results in older patients.

\section{NOSE}

\section{Clinical evaluation}

Feminization of the nose requires a detailed understanding of the conventional aesthetics of the nose, knowledge of key anatomical differences between males and females, and functional considerations $[39,40]$. The most prominent features of the male nose include a wide nasal bones, nostril flaring, a nasofrontal angle of approximately $130^{\circ}$, a higher radix positioned at the upper lid crease, and a nasolabial angle of approximately $90^{\circ}$ $[41,42]$. The female nose has a nasofrontal angle closer to $145^{\circ}$ with a radix closer to the mid-pupillary level, and an obtuse nasolabial angle. The male nasal tip is also projected approximately $5 \mathrm{~mm}$ more than the female nasal tip [43].

\section{General surgical considerations}

The approach to the feminizing rhinoplasty, as in any procedure, is dictated by the desired anatomical changes and the exposure needed to achieve the desired results. While an open rhinoplasty can provide easy access to the bony and cartilaginous framework of the nose, a closed approach may be sufficient in certain cases. A reduction of the dorsum is typically required and should be accompanied by adjunctive maneuvers to preserve internal and external nasal valve function $[44,45]$. Classic rhinoplasty reduction techniques alone, without these additional supportive measures, may risk long-term complications in the FFS patient, especially given the degree of reduction often needed [39]. It is therefore critical that any preoperative functional issues related to a deviated septum, nasal valve incompetence, and turbinate hypertrophy be identified and potentially included in the operative plan as any intervention may exacerbate underlying problems.

\section{Radix and dorsum}

At the same time as anterior table setback, the radix is typically reduced such that a smooth transition may be achieved between the frontal bone and the nose. The reduction of the radix is generally one of the more unique maneuvers of the reduction rhinoplasty in facial feminization as this is approached superiorly from the coronal approach rather than from the typical rhinoplasty approach. Depending on the patient, dorsal reduction is frequently necessary due to the overall projection of the more masculine nose compared to feminine noses. Berli and Loyo [42] suggested that the goal of dorsal reduction should be a nasal dorsum approximately 1-2 $\mathrm{mm}$ posterior to an imaginary line between the ideal nasal tip and the nasion.

\section{Nasal tip projection and the nasolabial angle}

The goals of nasal tip refinement include decreasing nasal tip projection, decreasing nasal width, and increasing tip rotation [42]. Typical techniques used to modify and rotate the nasal tip are those common to conventional aesthetic rhinoplasties, including resecting cephalic margins of the lower lateral crura to decrease projection, transdomal and intradomal sutures to narrow the tip, and modifications of the caudal septum, septal extension grafting, or columella strut grafting to rotate the tip and increase the nasolabial angle [46]. Frequently, for the purposes of stability in the change in tip rotation, particularly in the setting of a combined reduction rhinoplasty with upper lip lift, rib 
cartilage autograft or allograft will be necessary as a septal extension graft or columella strut.

\section{Width reduction}

Both the nasal bones and the alar base are wider in masculine noses compared to feminine noses. Hence, osteotomies are generally needed. Alar base width reduction via Weir and or sill excisions is typically undertaken when the alar base width is greater than intercanthal distance [42] and is the last step in the FFS rhinoplasty. Alar flaring can occur secondary to radical reduction of the nasal tip, requiring an alar base reduction during the initial operation. At the same time, aggressive resection is needed to decrease projection and alar flaring may risk alar retraction and collapse. Thus, prophylactic alar rim grafts may be necessary to maintain nasal aesthetics and external valve competence [42].

\section{CONCLUSIONS}

FFS is a rapidly progressing field that plays an important role during the gender transitioning process. As the face drives gender identification, understanding the hard and soft tissue differences between males and females as well as the wide variety of techniques used to transition is essential to optimize outcomes. Further, extensive preoperative evaluation by a multidisciplinary team is crucial for surgical planning and to ensure that the needs of patients are addressed adequately prior to and after surgery.

\section{NOTES}

\section{Conflict of interest}

No potential conflict of interest relevant to this article was reported.

\section{Author contribution}

Conceptualization: BN Dang, Justine C. Lee. Methodology: BN Dang, Justine C. Lee. Writing - original draft: BN Dang, AC $\mathrm{Hu}, \mathrm{AA}$ Bertrand, CH Chan, NS Jain, MJ Pfaff, James C. Lee, Justine C. Lee. Writing - review \& editing: BN Dang, AC Hu, AA Bertrand, CH Chan, NS Jain, MJ Pfaff, James C. Lee, Justine C. Lee

\section{ORCID}

Brian N. Dang https://orcid.org/0000-0003-4401-1361 Allison C. Hu https://orcid.org/0000-0003-4760-0292 Anthony A. Bertrand https://orcid.org/0000-0002-6986-4486 Candace H. Chan https://orcid.org/0000-0002-7281-4682 Nirbhay S. Jain https://orcid.org/0000-0003-4463-7479 Miles J. Pfaff https://orcid.org/0000-0003-2344-6294
James C. Lee https://orcid.org/0000-0002-5166-6940

Justine C. Lee https://orcid.org/0000-0002-8943-0837

\section{REFERENCES}

1. Lundgren KC, Koudstaal MJ. Midfacial bony remodeling. Facial Plast Surg Clin North Am 2019;27:221-6.

2. Ginsberg BA, Calderon M, Seminara NM, et al. A potential role for the dermatologist in the physical transformation of transgender people: a survey of attitudes and practices within the transgender community. J Am Acad Dermatol 2016; 74:303-8.

3. Ainsworth TA, Spiegel JH. Quality of life of individuals with and without facial feminization surgery or gender reassignment surgery. Qual Life Res 2010;19:1019-24.

4. Morrison SD, Capitan-Canadas F, Sanchez-Garcia A, et al. Prospective quality-of-life outcomes after facial feminization surgery: an international multicenter study. Plast Reconstr Surg 2020;145:1499-509.

5. Fisher M, Lu SM, Chen K, et al. Facial feminization surgery changes perception of patient gender. Aesthet Surg J 2020; 40:703-9.

6. James S, Herman J, Rankin S, et al. The report of the 2015 U.S. transgender survey [Internet]. Center for Victim Research Repository; c2016 [2020 Jun 18]. Available from: http://hdl.handle.net/20.500.11990/1299.

7. Pfaff MJ, Malapati SH, Su L, et al. A structured facial feminization fresh tissue surgical simulation laboratory improves trainee confidence and knowledge. Plast Reconstr Surg 2020;145:1016e-1017e.

8. Morrison SD, Chong HJ, Dy GW, et al. Educational exposure to transgender patient care in plastic surgery training. Plast Reconstr Surg 2016;138:944-53.

9. Coleman E, Bockting W, Botzer M, et al. Standards of care for the health of transsexual, transgender, and gender-nonconforming people, version 7. Int J Transgenderism 2012; 13:165-232.

10. Capitan L, Gutierrez Santamaria J, Simon D, et al. Facial gender confirmation surgery: a protocol for diagnosis, surgical planning, and postoperative management. Plast Reconstr Surg 2020; $145: 818 \mathrm{e}-828 \mathrm{e}$.

11. Fang F, Clapham PJ, Chung KC. A systematic review of interethnic variability in facial dimensions. Plast Reconstr Surg 2011;127:874-81.

12. Hoang H, Bertrand AA, Hu AC, et al. Simplifying facial feminization surgery using virtual modeling on the female skull. Plast Reconstr Surg Glob Open 2020;8:e2618.

13. Mandelbaum M, Lakhiani C, Chao JW. A novel application 
of virtual surgical planning to facial feminization surgery. J Craniofac Surg 2019;30:1347-8.

14. Pfaff MJ, Steinbacher DM. Plastic surgery applications using three-dimensional planning and computer-assisted design and manufacturing. Plast Reconstr Surg 2016;137:603e616 e.

15. Ousterhout DK. Feminization of the forehead: contour changing to improve female aesthetics. Plast Reconstr Surg 1987;79:701-13.

16. Habal MB. Aesthetics of feminizing the male face by craniofacial contouring of the facial bones. Aesthetic Plast Surg 1990; 14:143-50.

17. Somenek M. Gender-related facial surgical goals. Facial Plast Surg 2018;34:474-9.

18. Spiegel JH. Facial determinants of female gender and feminizing forehead cranioplasty. Laryngoscope 2011;121:25061.

19. Altman K. Facial feminization surgery: current state of the art. Int J Oral Maxillofac Surg 2012;41:885-94.

20. Capitan L, Simon D, Meyer T, et al. Facial feminization surgery: simultaneous hair transplant during forehead reconstruction. Plast Reconstr Surg 2017;139:573-84.

21. Capitan L, Simon D, Bailon C, et al. The upper third in facial gender confirmation surgery: forehead and hairline. J Craniofac Surg 2019;30:1393-8.

22. Deschamps-Braly JC. Facial gender confirmation surgery: facial feminization surgery and facial masculinization surgery. Clin Plast Surg 2018;45:323-31.

23. Di Maggio M. Forehead and orbital rim remodeling. Facial Plast Surg Clin North Am 2019;27:207-20.

24. Ousterhout DK. Aesthetic contouring of the craniofacial skeleton. 1st ed. Boston: Little, Brown; 1991.

25. Hoenig JF. Frontal bone remodeling for gender reassignment of the male forehead: a gender-reassignment surgery. Aesthetic Plast Surg 2011;35:1043-9.

26. Ousterhout DK, Zlotolow IM. Aesthetic improvement of the forehead utilizing methylmethacrylate onlay implants. Aesthetic Plast Surg 1990;14:281-5.

27. Yaremchuk MJ. Facial skeletal reconstruction using porous polyethylene implants. Plast Reconstr Surg 2003;111:181827.

28. Spiegel JH. Facial feminization for the transgender patient. J Craniofac Surg 2019;30:1399-402.

29. Villepelet A, Jafari A, Baujat B. Fronto-orbital feminization technique: a surgical strategy using fronto-orbital burring with or without eggshell technique to optimize the risk/benefit ratio. Eur Ann Otorhinolaryngol Head Neck Dis 2018; 135:353-6.
30. Altman K. Forehead reduction and orbital contouring in facial feminization surgery for transgender females. Br J Oral Maxillofac Surg 2018;56:192-7.

31. Benkhatar H, Khettab I, Sultanik P, et al. Mucocele development after endoscopic sinus surgery for nasal polyposis: a long-term analysis. Ear Nose Throat J 2018;97:284-94.

32. Morrison SD, Vyas KS, Motakef S, et al. Facial feminization: systematic review of the literature. Plast Reconstr Surg 2016; 137:1759-70.

33. Baudouin JY, Tiberghien G. Symmetry, averageness, and feature size in the facial attractiveness of women. Acta Psychol (Amst) 2004;117:313-32.

34. Gao Y, Niddam J, Noel W, et al. Comparison of aesthetic facial criteria between Caucasian and East Asian female populations: an esthetic surgeon's perspective. Asian J Surg 2018; 41:4-11.

35. Scawn R, Gore S, Joshi N. Blepharoplasty basics for the dermatologist. J Cutan Aesthet Surg 2016;9:80-4.

36. Cho SW, Jin HR. Feminization of the forehead in a transgender: frontal sinus reshaping combined with brow lift and hairline lowering. Aesthetic Plast Surg 2012;36:1207-10.

37. Adetayo OA, Wong WW, Motakef S, et al. Endoscopic brow lift fixation with Mitek suture anchors: a 9-year experience of a new "ideal” technique. Plast Surg (Oakv) 2019;27:1006.

38. Moody BR, Weber PJ. Blepharoplasty and brow lift. In: Robinson JK, Sengelmann RD, Hanke CW, et al., editors. Surgery of the skin: procedural dermatology. Philadelphia: Elsevier Mosby; 2005. p. 673-89.

39. Bellinga RJ, Capitan L, Simon D, et al. Technical and clinical considerations for facial feminization surgery with rhinoplasty and related procedures. JAMA Facial Plast Surg 2017; 19:175-81.

40. Robertson BD, Lerner BS, Collen JF, et al. The effects of transgender hormone therapy on sleep and breathing: a case series. J Clin Sleep Med 2019;15:1529-33.

41. Tanna N, Nguyen KT, Ghavami A, et al. Evidence-based medicine: current practices in rhinoplasty. Plast Reconstr Surg 2018;141:137e-151e.

42. Berli JU, Loyo M. Gender-confirming rhinoplasty. Facial Plast Surg Clin North Am 2019;27:251-60.

43. Dempf R, Eckert AW. Contouring the forehead and rhinoplasty in the feminization of the face in male-to-female transsexuals. J Craniomaxillofac Surg 2010;38:416-22.

44. Deschamps-Braly JC. Approach to feminization surgery and facial masculinization surgery: aesthetic goals and principles of management. J Craniofac Surg 2019;30:1352-8.

45. Noureai SA, Randhawa P, Andrews PJ, et al. The role of na- 
sal feminization rhinoplasty in male-to-female gender reassignment. Arch Facial Plast Surg 2007;9:318-20.

46. Di Maggio MR, Nazar Anchorena J, Dobarro JC. Surgical management of the nose in relation with the fronto-orbital area to change and feminize the eyes' expression.J Craniofac Surg 2019;30:1376-9. 